\title{
Diferentes fotografias do cotidiano: o gênero crônica na Olimpíada
}

Clóris Porto Torquato*

* Universidade Estadual de

Ponta Grossa

\section{Resumo}

Este artigo integra o dossiê

A produção de textos

na Olimpíada de Língua

Portuguesa. Em consequência, pressupõe o conhecimento dos pressupostos teóricos e metodológicos da própria Olimpíada, tais como caracterizados na "Introdução" ao dossiê. A análise incidiu sobre 383 produções de alunos do nono ano do Ensino Fundamental e do primeiro ano do Ensino Médio público; e tomou como objeto de análise as marcas textuais do "diálogo" travado pela escrita discente com as orientações do caderno de orientação docente para 0 gênero em foco.
Este artigo analisa crônicas produzidas por estudantes brasileiros que participaram da Olimpíada em 2010. Inicialmente, à luz dos estudos bakhtinianos, procura-se refletir sobre a crônica a partir das orientações didáticometodológicas fornecidas para o ensino da produção desse gênero no material de formação dos professores da Olimpíada - o Caderno do Professor A ocasião faz o escritor. Em seguida, a partir dos conceitos de gênero do discurso e de dialogismo, são analisados alguns textos produzidos pelos candidatos. A análise indica que muitos textos dialogam com as orientações do Caderno do Professor, apresentando os elementos composicionais do gênero explicitados nesse material. Outros textos apresentam algumas características do gênero que não são abordadas no material, mas que podem ser identificadas em textos desse gênero em circulação nos jornais.

Palavras-chave: Crônica. Estudos bakhtinianos. Produção escrita. Formação de professores. 


\section{INTRODUÇÃO}

Para apresentarmos os resultados parciais de uma pesquisa sobre uma amostra de 383 crônicas produzidas por estudantes na Olimpíada retomaremos, primeiramente, algumas reflexões sobre esse gênero e sobre seu ensino, com o objetivo de analisar, à luz dos estudos bakhtinianos, as propostas do material que levam o professor a ensinar esse gênero.

Partiremos do pressuposto de que a Olimpíada, ao buscar desvincular-se de uma visão restritiva que focalize apenas o concurso, caracteriza-se como um "programa de formação" de professores, já que "vai muito além de um concurso de textos", ao propor aos "professores mudanças nas práticas de ensino de língua portuguesa” (MADI, 2005, p. 14). É assim que o Caderno do Professor A ocasião faz o escritor (CENPEC, 2010) integra parte do material que orienta o professor quanto às etapas do processo do concurso, fornecendo tanto as orientações relativas à produção textual como os critérios de avaliação dos textos para o concurso, constituindo-se, portanto, como um enunciado que integra o conjunto de discursos de formação de professores. Da mesma forma, constitui-se também como um material formador tanto de professores quanto de estudantes, na medida em que propõe uma sequência didática a ser realizada em sala de aula com os estudantes. Portanto, indiretamente, via professor, faz também a formação dos estudantes.

Como veremos na análise da amostra realizada em seguida, algumas crônicas aproximam-se das orientações do Caderno do Professor, enquanto outras parecem afastar-se destas.

\section{ASSUNTO-PUXA-ASSUNTO}

Para tratar do gênero crônica, é interessante perceber, primeiramente, que algumas caracterizações do gênero bastante esclarecedoras são aquelas produzidas pelos próprios cronistas, como esta de Carlos Drummond de Andrade, em entrevista inédita publicada pela Revista Caros Amigos:

Conforme aponta o próprio Caderno, "Preparamos, para seu uso, uma série de onze oficinas, que, trabalhadas em salas de aula, constroem passo a passo as habilidades para se escrever uma crônica.” (CENPEC, 2010, p. 22) 
A crônica é fruto do jornal, onde aparece entre notícias efêmeras. Trata-se de um gênero literário que se caracteriza por estar perto do dia-a-dia, seja nos temas, ligados à vida cotidiana, seja na linguagem despojada e coloquial do jornalismo. Mais do que isso, surge inesperadamente como um instante de pausa para o leitor fatigado com a frieza da objetividade jornalística. (...). Se a notícia deve ser sempre objetiva e impessoal, a crônica é subjetiva e pessoal. Se a linguagem jornalística deve ser precisa e enxuta, a crônica é impressionista e lírica. Se o jornalista deve ser metódico e claro, o cronista costuma escrever pelo método da conversa fiada, do assunto-puxa-assunto, estabelecendo uma atmosfera de intimidade com o leitor (ANDRADE, 1999, p.13, grifos nossos.).

O escritor, ao falar sobre seu fazer literário, reflete sobre a crônica que, dessa perspectiva, se constitui no/pelo entrecruzamento e contraposição entre a literatura (uma vez que é um "gênero literário") e o jornalismo ("fruto do jornal") para tratar do cotidiano. Dessa forma, Drummond nos auxilia a compreender a crônica como um gênero literário marcado pelo diálogo com outro gênero (notícia) que compõe o jornalismo, diálogo identificado tanto no que se refere ao tema quanto no que se refere à linguagem dos textos.

Assim como vários textos que se ocupam do estudo da crônica, o Caderno do Professor $A$ ocasião faz o escritor também aborda esse caráter fronteiriço do gênero, ressaltando a plasticidade e a fluidez dessa fronteira, estabelecendo algumas características do gênero a partir, sobretudo, das reflexões dos cronistas.

\section{O GÊNERO CRÔNICA No CADERNO do PROFESSOR A OCASIÃO FAZ O ESCRITOR}

O Caderno é dividido em onze capítulos, que apresentam onze oficinas a serem realizadas pelos professores com seus alunos; os capítulos são organizados de modo a garantir a didatização do gênero crônica na forma de uma sequência didática. Assim, cada capítulo focaliza um aspecto da preparação do estudante para a Olimpíada e volta-se para um aspecto do gênero, com destaque para os elementos internos.

No capítulo 1, reforça-se o aspecto contextual da produção/circulação do gênero: quem é o autor, em que situação o texto é produzido, para que interlocutores, com que objetivos/finalidades. Nos capítulos 3 a 8 e 10, são enfatizados aspectos internos ao gênero: escolhas temáticas, figuras de linguagem, escolhas linguísticas (estilísticas) que dão o tom do texto (humor, lirismo, ironia, crítica etc.). Nos capítulos 2, 9 e 11, articulam-se aspectos internos e externos ao texto, buscando explicitar a relação entre as escolhas linguísticas e os elementos do contexto em que a crônica é produzida. 
Em cada oficina, indicam-se as perguntas a serem feitas sobre as crônicas lidas/analisadas; nas oficinas voltadas à produção do texto, orientamse as atividades de escrita e de reescrita. Dentre as questões de leitura, observamos questões relativas à apreciação dos leitores em relação ao texto lido (sentidos produzidos pelo texto) e questões relativas ao gênero (autor, situação e objetivos de produção, tema/assunto, elementos da estrutura narrativa, recursos linguísticos). No que se refere à reescrita, o Caderno salienta os elementos internos do gênero crônicas literárias:

\section{ROTEIRO PARA A REVISÃO DA CRÔNICA}

- O cenário da crônica reflete o lugar onde você vive?

- Ela cumpre o objetivo a que se propõe: emocionar, divertir, provocar reflexão, enredar o leitor? (...)

- Organiza a narrativa em primeira ou terceira pessoa?

- As marcas de tempo e lugar que revelam fatos cotidianos estão presentes?

- Que tom o autor usa ao escrever: irônico, humorístico, lírico, crítico?

- Utiliza uma linguagem simples, espontânea, quase uma conversa informal com o leitor?

- O enredo da crônica está bem desenvolvido, coerente? Há uma unidade de ação?

- No desenrolar do texto as características da narrativa (personagem, cenário, tempo, elemento surpresa ou conflito e desfecho) estão presentes?

- Faz uso de verbos de dizer?

- Os diálogos das personagens são pontuados corretamente? (...)

- O título mobiliza o leitor para leitura?

(CENPEC, 2010, p. 124, grifos nossos)

Embora o Caderno também contemple os aspectos extraverbais que sustentam as escolhas internas do texto, a maior parte dos critérios referese a elementos internos, especialmente elementos linguísticos. Quanto aos elementos da estrutura textual/composicional do gênero, destacam-se elementos próprios das narrativas: foco narrativo, "enredo, personagens, cenário, tempo, conflito, desfecho”. Esses critérios são coerentes com o recorte feito para o ensino do gênero: o foco está nas crônicas literárias.

E como a crônica é apresentada ao professor? Primeiramente, como um gênero veiculado no jornal: "um dos prazeres da vida é abrir o jornal num 
domingo preguiçoso, pular as seções de política e economia e ler, sem compromisso, uma crônica" (CENPEC, 2010, p. 17, grifos nossos). A vinculação da crônica ao jornal também é abordada a partir do diálogo da crônica com as notícias, marcado pela particularidade da apreensão que alguns cronistas fazem dos assuntos abordados nas notícias, no jornal. 0 vínculo da crônica com o jornal pode ser observado em diferentes partes do Caderno, especialmente nas orientações para a produção do texto pelo aluno:

\section{[Professor,] Traga alguns exemplos de assuntos que circularam nos jornais $e$ poderiam dar boas crônicas. (...) Agora, peça aos alunos, divididos em grupos, que levantem cinco assuntos que estão em voga na cidade, nas conversas da praça, nos bate-papos do bar, nas discussões sobre futebol (...). Podem ser também fatos noticiados em jornais, revistas, emissoras de rádio da localidade. (...) Peça aos alunos que, tendo escolhido o fato, a situação ou a notícia que vai ser foco da crônica (...). (CENPEC, 2010a, p. 88-89, grifos nossos)}

Sugere-se assim que os temas e os assuntos tratados nos textos sejam oriundos tanto do conteúdo das conversas cotidianas quanto dos textos veiculados no jornal. Essa sugestão parece estar baseada na perspectiva de que o cronista é o observador do cotidiano, o qual também é objeto do jornal. Assim, tanto o jornal quanto as conversas cotidianas alimentam o fazer do cronista.

Salienta-se que a crônica caracteriza-se pela flexibilidade: “crônica é um gênero de texto tão flexível que pode usar a ‘máscara' de outros gêneros, como o conto, a dissertação, a memória, o ensaio ou a poesia, sem se confundir com nenhum deles" (CENPEC, 2010, p. 20). Assim, o Caderno designa, entre as diferentes "máscaras" sob as quais a crônica pode aparecer, gêneros que fazem parte de campos diferentes: o conto, a memória e a poesia estão no campo da literatura; a dissertação está no campo dos gêneros propriamente escolares, embora o caráter argumentativo do texto possa fazer parte de diferentes gêneros, inclusive alguns gêneros jornalísticos, como o artigo e a carta do leitor; o ensaio pode estar no campo jornalístico e no campo acadêmico.

Além destes, também explicita-se o diálogo entre o gênero crônica e o gênero notícia, como se pode observarna pergunta orientadora da discussão para definição da temática da crônica a ser produzida coletivamente: "Como essa notícia pode ser transformada em uma crônica?” (CENPEC, 2010, p. 108). Esse diálogo pode ser observado também no capítulo 6, intitulado "Trocando em miúdos", no qual apresenta-se uma manchete publicada no jornal Folha de S. Paulo e orienta-se o professor a recuperar com seus alunos os objetivos do gênero notícia e, em seguida, a analisar uma crônica de Moacir Scliar cujo tema está relacionado com a manchete apresentada anteriormente. Essas atividades visam "reunir características das notícias e compará-las com as das crônicas” (CENPEC, 2010, p. 75). 
Assim, ao assinalar as possibilidades de construção do gênero crônica e ao explicitar o diálogo entre a crônica e a notícia, o Caderno auxilia seus interlocutores a construir uma compreensão da crônica como um gênero caracteristicamente fronteiriço e flexível.

$\mathrm{Na}$ caracterização do gênero, o Caderno também retoma, mesmo sem explicitar as fontes ${ }^{2}$ no decorrer do texto, estudos sobre a crônica realizados por Antonio Candido (1981; 1992), Davi Arrigucci Junior (1987) e Jorge de Sá (1985), citados nas Referências. Com base nesses autores, a crônica é definida no Caderno como:

um gênero que retrata os acontecimentos da vida em tom despretensioso, ora poético, ora filosófico, muitas vezes divertido. Nossas crônicas são bastante diferentes daquelas que circulam em jornais de outros países. Lá são relatos objetivos e sintéticos, comentários sobre pequenos acontecimentos, e não costumam expressar sentimentos pessoais do autor. Os cronistas brasileiros exprimem vivências e sentimentos próprios do universo cultural do país.

No Brasil, há vários modos de escrevê-las. Se usa o tom da poesia, o autor produz uma prosa poética, como algumas crônicas escritas por Paulo Mendes Campos. Mas elas podem ser escritas de uma forma mais próxima ao ensaio, como as de Lima Barreto; ou a que você acabou de ler, de Ivan Ângelo; ou ser narrativas, como as de Fernando Sabino. As crônicas podem ser engraçadas, puxando a reflexão do leitor pelo jeito humorístico, como as de Moacyr Scliar, ou ter um tom sério. Outras podem ser próximas de comentários, como as crônicas esportivas ou políticas.

Dessa forma, o Caderno resume a diversidade de classificação das crônicas de diferentes estudiosos, apontando apenas algumas classificações com base nas características internas dos textos ("prosa poética”, "ensaio" e “narrativas") e nos efeitos de sentido a serem produzidos ("engraçadas" e "tom sério") no leitor.

Ainda na tentativa de informar ao leitor/professor sobre o gênero, indica-se que as crônicas, sendo "publicadas em jornais e revistas", nesse contexto de produção e circulação, "são lidas apenas uma vez e, em geral, esquecidas pelo leitor” (CENPEC, 2010a, p. 21). Dessa forma, salienta-se a transitoriedade

É possível que, no Caderno, não sejam feitas citações dos textos dos estudiosos nem referências aos autores da área de estudos literários devido a uma tentativa de produzir um texto não acadêmico. Assim, embora o texto do Caderno tenha sido construído no diálogo com textos acadêmicos e esteja teoricamente fundamentado em textos do campo dos estudos literários, esse diálogo não está linguisticamente marcado. No Caderno, inclusive, os textos que auxiliam na definição do gênero são produzidos pelos próprios cronistas. Essa escolha acaba por provocar no leitor a impressão de que a caracterização do gênero apresentada no Caderno decorre unicamente dos textos (das definições) dos cronistas. 
que marca a maior parte das crônicas. $\mathrm{E}$, diante da diversidade característica do gênero, o Caderno parece definir um recorte a ser privilegiado: a crônica literária3, que "tem longa duração e é sempre apreciada pelo estilo de quem a escreve e pelo tema abordado" (CENPEC, 2010a, p. 21).

Assim, embora indique o vínculo do gênero com o jornal e a revista e indique o diálogo da crônica com a notícia, o Caderno prioriza para o ensino aqueles textos que permanecem, que não perdem a atualidade, seja pela linguagem, seja pelo modo de abordar a temática. Parece ser decorrente dessa escolha a seleção dos textos citados no material: o Caderno reproduz e faz referência a crônicas publicadas em livros. Esse aspecto deve ser salientado porque a escolha pelas crônicas que se tornam permanentes gera consequências para as orientações relativas ao ensino do gênero no Caderno e para a construção dos critérios para produção e avaliação dos textos dos estudantes/candidatos na Olimpíada.

A permanência da crônica está frequentemente relacionada com a mudança de suporte: “Uma vez publicada em livro, a crônica assume uma certa reelaboração, na medida em que é escolhida pelo Autor (em alguns casos, é outra pessoa quem organiza a coletânea). Além disso, ela se torna mais duradoura, porque os textos que envelheceram devido à sua excessiva circunstancialidade não entram na seleção" (SÁ, 1985, p. 84).

Essa mudança gera, especialmente, a possibilidade de novas e mais profundas leituras dos textos (SÁ, 1985), que já não estão presos à situação inicial de produção e circulação. Essa "reprodução do texto pelo sujeito (a retomada dele, a repetição da leitura, uma nova execução, uma citação) é um acontecimento novo e singular na vida do texto, o novo elo na cadeia histórica da comunicação discursiva” (BAKHTIN, 2003b, p. 311). E, como afirma Sá, este novo acontecimento está interligado a um novo modo de ler:

\footnotetext{
a mudança de suporte provoca um novo direcionamento: o público do jornal é mais apressado e mais envolvido com várias matérias focalizadas pelo periódico; o público do livro é mais seletivo, mais reflexivo até pela possibilidade de escolher um momento mais solitário para ler o autor de sua preferência. Em muitos casos, o público chega a ser basicamente igual, uma vez que o mesmo leitor que frui a vida através das reportagens também a fruirá através das páginas literárias: a atitude diante do texto é que muda. (1985, p. 85)
}

No Caderno, a crônica definida como literária é aquela que supera a transitoriedade e torna-se permanente, normalmente sendo publicada em livros. Nesse sentido, o Caderno parece indicar que é possível estabelecer um contínuo, dentre a diversidade das crônicas, que vai de crônicas mais propriamente literárias a crônicas mais propriamente jornalísticas. Tal contínuo teria como principais critérios distintivos o trabalho com a linguagem, com o caráter estético do texto e com a temática abordada (temáticas mais ou menos circunstanciais, portanto, mais ou menos datadas).

cadernoscenpec | São Paulo | v.2 | n.1 | | julho 2012 
Se, por um lado, a escolha pelas crônicas que permanecem pode gerar mudança de atitude do leitor e possibilidade de outras leituras, por outro lado, no que se refere ao ensino, é importante observar que a produção de crônicas no jornal vai muito além das crônicas literárias. Mesmo escritores reconhecidos nem sempre produzem crônicas que resistem ao tempo. Na produção diária de crônicas são relativamente poucas as que superam a circunstancialidade do jornal. É em virtude desse caráter predominantemente transitório/circunstancial que Candido afirma:

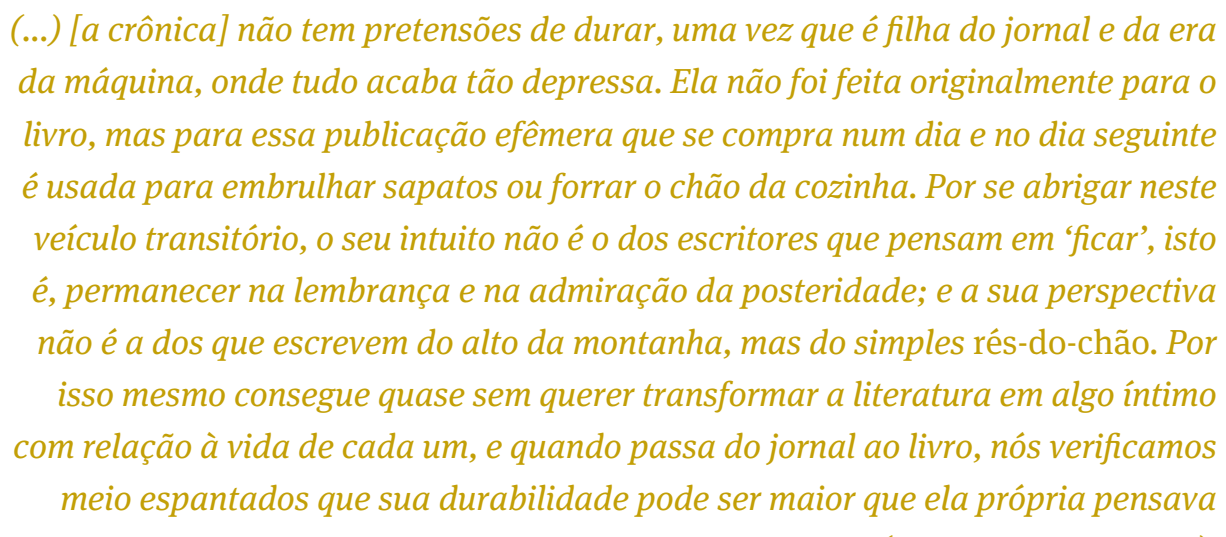

(CANDIDO, 1981, p. 6).

Assim, no ensino, se o objetivo é proporcionar ao aluno possibilidades de leituras críticas, aprofundadas, e promover a formação do leitor de literatura, começando por textos que transformem “a literatura em algo íntimo com relação à vida”, a crônica literária que permanece parece ser o gênero indicado a ser didatizado.

Por outro lado, embora possam ser mais produtivas as leituras dos textos que permanecem, as práticas efetivas de leitura do jornal podem colocar o aluno/ leitor em contato mais frequente com crônicas que podem não permanecer e/ou não ter a estrutura e os recursos linguísticos da crônica literária. Assim, a leitura dos textos do jornal (notícias, textos de opinião e crônicas), tão necessária à realização da sequência didática no ensino do gênero crônica, pode colocar o aluno/leitor em contato com crônicas com diferentes “máscaras”: crônica-ensaio, crônica-comentário, crônica-informação.

O Caderno parece contemplar essa possibilidade, pois há indícios (marcas linguísticas) de que o aluno/leitor poderá produzir crônicas com essas diferentes máscaras: na tabela em que apresenta o detalhamento dos critérios ${ }^{4}$ para avaliação dos textos dos alunos, o Caderno refere-se a diferentes

\footnotetext{
Vale indicar que os critérios foram elaborados com a colaboração de professores de universidades públicas (ver CENPEC, 2010, p. 126). Portanto, os critérios revelam o diálogo entre as autoras do texto do Caderno e os professores universitários. Nesse diálogo, expande-se a perspectiva de trabalho com as crônicas, ampliando-se as possibilidades de didatização do gênero.
} 
estruturas textuais em função do "tipo de crônica escolhido (política, cultural, esportiva...)" e o uso de diferentes articuladores textuais "apropriados ao tipo de crônica escolhido pelo autor" (CENPEC, 2010, p. 127, grifos nossos). 5

A possibilidade de produção dessas outras variedades de crônicas aponta para um aspecto importante da formação promovida pelo programa: 0 professor é orientado para conhecer e didatizar os elementos que compõem o gênero crônica literária. Em virtude dessa formação, o professor passa a reconhecer os procedimentos de análise e de didatização de outros textos, sendo formado para empreender, de modo autônomo, análises e didatizações tanto de outras variedades do mesmo gênero quanto de outros gêneros. Nesse caso, o professor teria autonomia para explorar os elementos característicos desses outros tipos de crônica e para didatizá-los.

Assim, a efetiva inserção na prática social de leitura de textos do jornal promovida pela sequência didática colocaria o professor e os estudantes diante de outras variedades de crônicas; e, portanto, da possibilidade de análise e produção dessas variedades. E as análises dos textos produzidos pelos candidatos na Olimpíada indicam que essa possibilidade pode ter sido concretizada, pois boa parte dos textos produzidos não se encaixam na categoria crônica literária, mas, ainda assim, poderiam ser considerados crônicas.

\section{OS TEXTOS CONCORRENTES NO GÊNERO CRÔNICA NA OLIMPÍADA}

Nossa análise procura levar em consideração, entre outros aspectos, a situação de produção e circulação dos textos, que está interligada à intenção com a qual o texto é produzido em relação a um interlocutor, e o diálogo entre diferentes textos.

Quanto à situação de produção, os textos da amostra parecem ser duplamente orientados: os candidatos são motivados a escrever para o concurso da Olimpíada, portanto, para diferentes bancas avaliadoras, ${ }^{6}$ e também são orientados a escrever para sua comunidade escolar. No Caderno, define-se a seguinte situação de comunicação: “cada um dos alunos é um autor que vai

Os trechos em destaque indicam que o aluno/autor, embora tenha sido orientado pelas oficinas predominantemente para as literárias, pode produzir outros tipos de crônicas, especialmente os mais próximos do jornalismo que da literatura.

São várias as bancas avaliadoras nas diferentes instâncias do processo seletivo: para além da avaliação na própria turma, os textos são avaliados por professores na escola e por sujeitos envolvidos com educação nas instâncias municipais, estaduais e nacionais do concurso. 
escrever sobre situações do lugar onde vivem para colegas, educadores, pais e familiares" (CENPEC, 2010, p. 115, grifos nossos).

Observa-se, assim, que os estudantes são orientados a produzir seus textos para a comunidade, mas esses mesmos textos serão avaliados (tanto pelos colegas de classe quanto pelas bancas avaliadoras) para o concurso da Olimpíada. Em relação a esses diferentes grupos de interlocutores (leitores avaliadores e/ou comunidade escolar), são estabelecidos propósitos/ intenções distintos; junto aos avaliadores, busca-se classificação nas diferentes etapas do concurso; junto à comunidade escolar, pretende-se refletir sobre diferentes aspectos do cotidiano em que se vive, a partir do humor, do lirismo, da crítica.

Nesse sentido, pode-se observar que a produção de um texto está vinculada ao processo de interlocução no sentido de que a resposta do interlocutor/ leitor orienta a própria produção textual. Como afirma Bakhtin (2003a), "é como se todo o enunciado se construísse ao encontro dessa resposta"; por isso, "um traço essencial (constitutivo) do enunciado é o seu direcionamento a alguém, o seu endereçamento" (p. 301). Compreendemos, assim, que na produção de crônicas na Olimpíada tanto o recorte do cotidiano (a delimitação no interior de um tema) quanto o tom que se quer imprimir aos textos estão vinculados à situação de produção do texto e ao endereçamento aos leitores (comunidade escolar e avaliadores).

Um dos aspectos que parece indicar o endereçamento dos textos dos alunos às bancas avaliadoras é o tratamento dispensado ao conteúdo temático; é possível que, em função de a Olimpíada ter definido como tema das produções textuais "O lugar onde vivo", muitos alunos tenham descrito praças, ruas ou cidades, visando à interlocução com as bancas avaliadoras, que possivelmente desconhecem o cotidiano dos alunos/autores. Em virtude do tema e dirigindo-se a leitores que desconhecem sua realidade, alguns alunos produziram textos predominantemente descritivos.

$\mathrm{Na}$ tentativa de apresentar e descrever positivamente o lugar, especialmente sua cidade, alguns autores produziram textos que se aproximam - pelo estilo e conteúdo temático - daqueles publicados em cadernos de jornal e a revistas dedicadas a viagens e turismo, com o objetivo de apresentar e divulgar determinado destino, como se observa no texto abaixo: 
O lugan ounde rinie

Mons em , wema cidade mui-

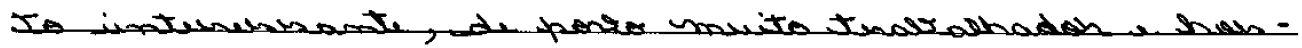
pitalaitos.

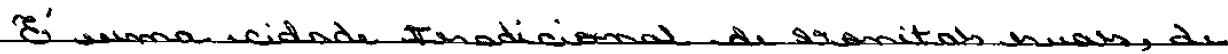

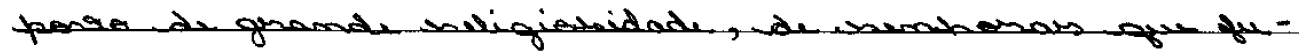

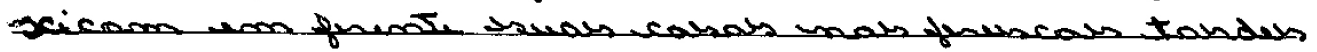

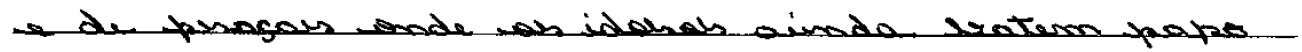

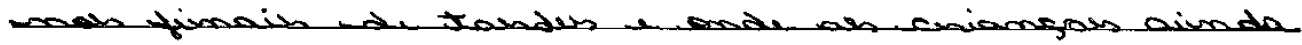

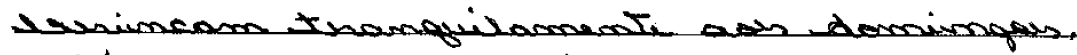

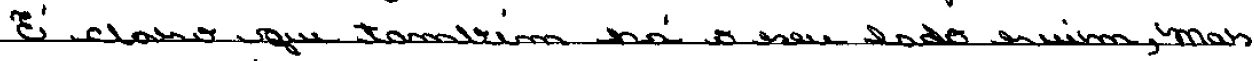

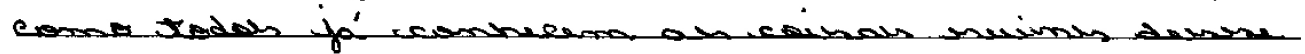

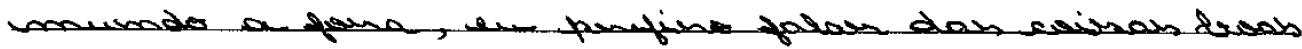

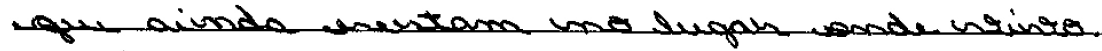

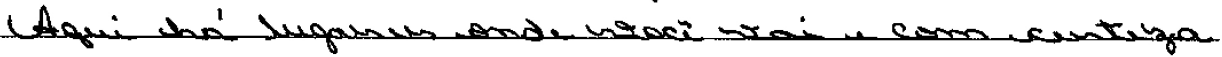

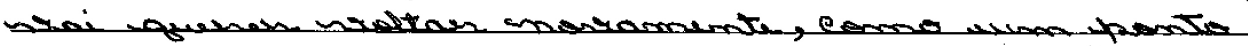

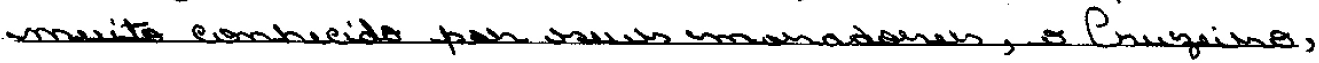

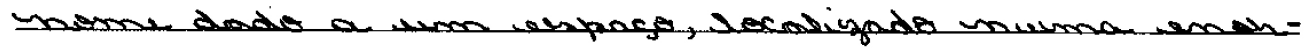

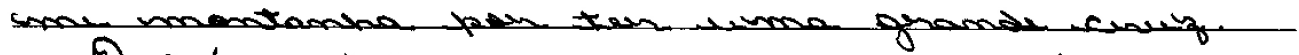

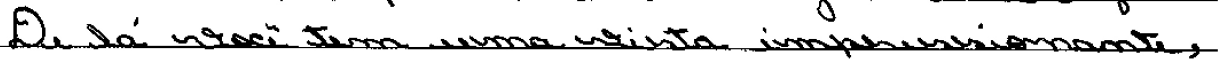

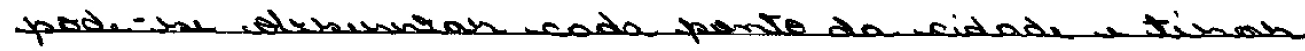

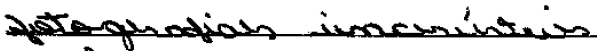

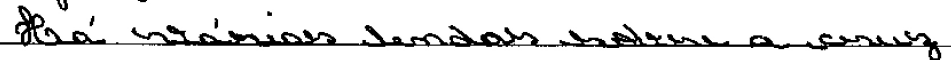

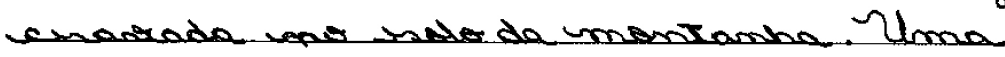

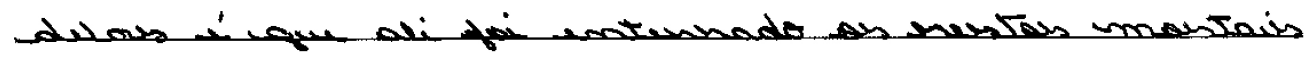

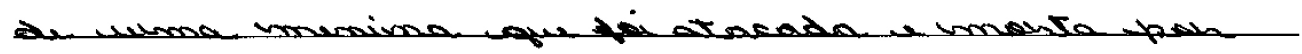

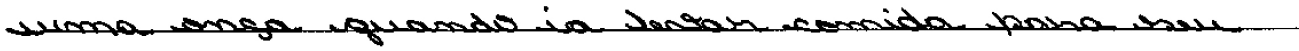

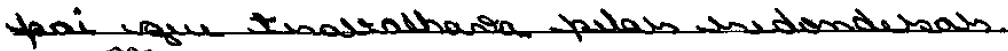

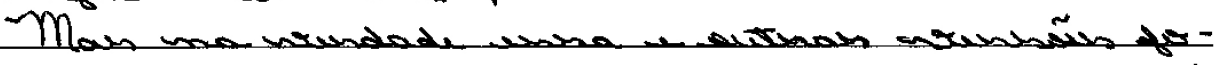

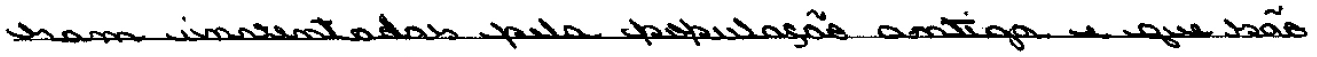

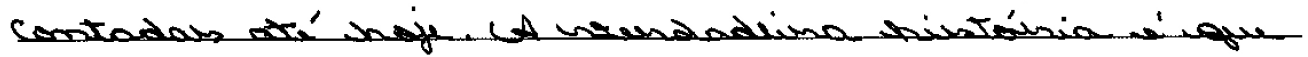

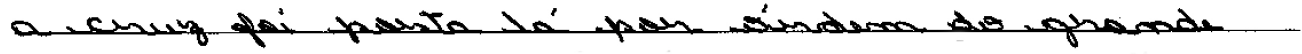

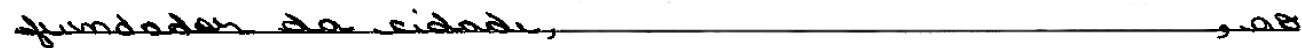

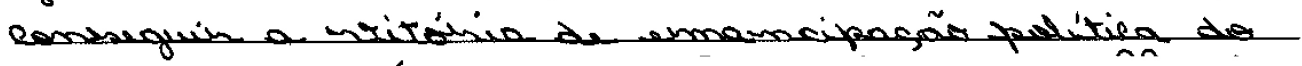

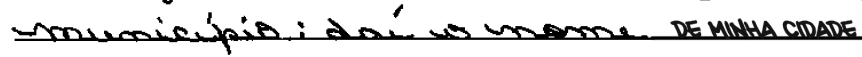

\section{A.F.S., aluna-autora}

Nesse texto, como em vários outros da amostra, o candidato ocupou-se da apresentação e da promoção de sua cidade e, especialmente, de um ponto turístico. De modo a divulgar favoravelmente sua cidade, o autor utilizou recursos linguísticos que caracterizam positivamente tanto a cidade quanto o povo: "cidade muito interessante", "povo muito trabalhador e hospitaleiro" 
e "bonitas ruas". Em outros textos, com construção semelhante, foram divulgados lugares considerados bonitos e atividades atrativas na cidade ou no bairro. Para divulgação, os autores frequentemente utilizaram expressões que caracterizam a cidade e seus moradores de modo positivo, sendo recorrentes expressões como agradável, adorável, simpática e acolhedora, para descrever a cidade; e alegres, simpáticos, afetuosos e hospitaleiros para qualificar os moradores. Outros textos descreveram lugares com o objetivo de criticar os problemas locais, conferindo, pelas escolhas das palavras, um tom crítico ao texto. Nesses casos, assim como nos textos elogiosos, a descrição predomina sobre a narração.

A preocupação dos autores em descrever pormenorizadamente os lugares onde vivem pode revelar sua expectativa de que seus leitores sejam avaliadores que desconhecem o lugar, como se observa no quarto parágrafo do texto acima: “Aqui há lugares onde você vai e com certeza vai querer voltar novamente, como um ponto muito conhecido por seus moradores, o Cruzeiro (...)". As palavras em destaque parecem indicar que o aluno estabeleceu a interlocução com um leitor que desconhece o local citado. Parece-nos, portanto, que esse aluno não tem nem sua comunidade escolar, nem interlocutores que partilhem o conhecimento do lugar/cenário descrito em seu horizonte.

Outro fator que pode provocar o predomínio de estruturas descritivas nos textos é uma possível dificuldade de o aluno recortar um aspecto particular do cotidiano, de modo a apurar o olhar a respeito. Embora a oitava oficina proposta no Caderno concentre o trabalho nessa tarefa, a análise indica que muitos estudantes ainda demonstram dificuldade na delimitação do foco, como se pode observar no segundo parágrafo do texto acima: descrevendo desde as ruas aos grupos de pessoas, o autor procura fornecer a seu interlocutor uma visão geral da cidade.

O texto reproduzido abaixo é um exemplo significativo deste tipo de texto, em que o observador procura captar, descritivamente, tudo que está à sua volta. 
C. Rura

Jarios wiancas cerrendo una Rua, la uyfia is

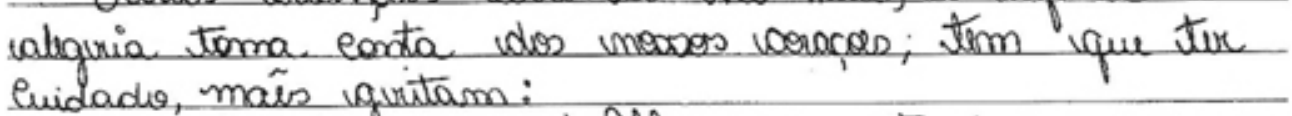

- mininos! menimos! Wham in ustrada. - Vá pula cantinho.

Carros passando toda hora, umas divagar Drempare valquiém lai u ver machuca porím mada veirio. Muninos dogando brda em varande terrers ude eimente, guntaria pana lá! quitaria para lá! E tudve vacalra un uma varande "Rilada". Hó varmpore valguém upana lager yum Barraco, quando mäo e brige e' qunte "brlbada" querendo

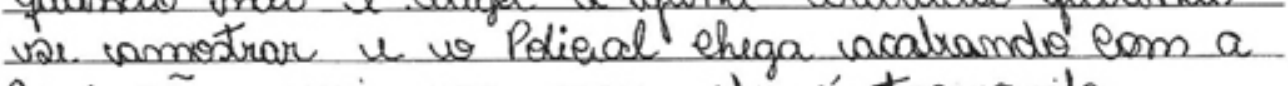

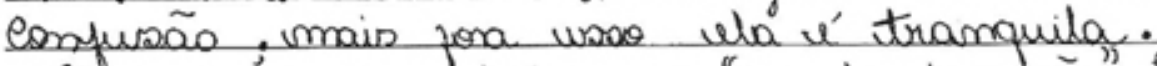

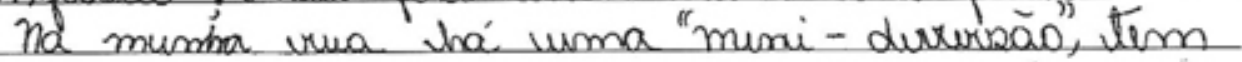
dón bramquimhon e uma mea de domino' bum lem lroivar de uma árnvore uque tem conno vapulido "Bance da fogeca", onde lá Judo vae imrenta.

Com todos usses deferentes umomentios náo devas ute lugar onde viaro noma puequena uxu, mas que tim un girande conação.

\section{A.M.S., aluna-autora}

À medida que tenta observar e fixar uma grande quantidade de eventos, o observador apenas os enumera: "crianças correndo"; "mães gritando"; "carros passando"; "queda”; "meninos jogando"; "gritaria”; "gente fazendo barraco"; "ação da polícia”. A rua é apresentada pelo autor a partir de "todos esses diferentes momentos" (caracterizados pelo uso do gerúndio como ações em desenvolvimento), que compõem a fotografia que permite ao leitor visualizar a rua.

Também em outros textos o autor procura apresentar quase tudo que acontece no cenário, como se uma observação detalhada resultasse numa apreensão mais global das cenas. Assim, estando numa praça, o observador descreve os namorados, a brincadeira das crianças, o jogo dos velhos e as voltas dos jovens solteiros em volta da praça. No entanto, nessa tentativa de apreensão do todo não se fixa em nada especial; nada é destacado. São apresentadas/ descritas cidades inteiras: os lugares históricos, os lugares de passeio, as diferentes atividades dos cidadãos (velhos, jovens, crianças); no entanto, nada merece atenção especial, nada faz refletir ou encanta. É como se o autor 
apresentasse ao leitor grandes fotografias com foco aberto que captam o cotidiano da rua ou da cidade sem focar um detalhe em especial.

Essa dificuldade de recortar o cotidiano gera consequências para a produção do texto: a) não se pode identificar um enredo; b) não há elemento surpresa ou conflito nem desfecho; c) o objetivo do texto parece ser apresentar ao leitor o lugar onde vive, não sendo possível identificar outros propósitos, como “emocionar, divertir, provocar reflexão, enredar o leitor”(CENPEC, 2010, p.124).

No entanto, uma vez que não narram nenhum episódio específico, esses textos descritivos dificilmente se encaixariam no gênero crônica literária, cuja estrutura característica é a narração. Associada à narração, é feita a descrição - do cenário e/ou das personagens -, mas dificilmente a descrição predomina sobre a narração. No caso de crônicas políticas e desportivas, por exemplo, associam-se à narração algumas estruturas mais argumentativas, informativas ou de comentário.

Os textos predominantemente descritivos produzidos pelos alunos, portanto, afastam-se das orientações do Caderno. E, como vimos, esse afastamento pode ser motivado, entre outros fatores (como a não execução das oficinas do modo como foi proposta no material), pelo processo de interlocução instaurado na produção textual, especialmente pelo endereçamento do texto.

Por sua vez, a descrição articulada à narração ajuda o leitor a visualizar os personagens que fazem parte da narrativa e o cenário onde se desenvolve o enredo. A seguir apresentamos um texto exemplar da articulação entre narração e descrição. 
Atorcedora

Lordei ao som da percussâd matinal na cosinha, anunciando que minha môe comegara cedo as atividades domesticats. Gafé cheiros $\theta$, quentinho. Mas era brom continuar ma cama. Muito cedol Admiti. Na"s demorlou muito escutei o resmungo da mamoie "Gen-

1 dia comesaria com um toque de ansiedade para minha mâs s outros milhares de brasileiros: era dia de fogo da Selecas banarinho. Para falar a cordade, futebrol a minhra mas só curte de quatro en quatro anos, momento da bopa do Mundo, perque, segundo ela mesma, "jogo bé da sele cas brasibira". dí sim, nã lem comrersa, incorpora o espúrito da pátria de chuteiras \& surpreende, quando temos a felicidade de um gol.

Tenho de admitir que, nesse dia, a mamáe estara ainda mais inspirada i can tarolava no ritmo da ansiedade e da luta na axk-

majais da casa.
A sala estaria pronta: codeiras em maior nímero para
acolher convidados e nă - convidados. acolher convidados \& nẫ-convidados.

Kossa rua dis pensa convite e cerimeñnia. Vizinho que é arizinto now precisa pedir licenga: é de casa, pede entrar \& acomedar-se. \& num momento desses, ainda mais acreditando num aperitivio a tazer jus a alegria de um gol brasileiro, ébala cheia.

Ras, ende estaria a mamår? O jogo ia comegar.

Ve compo, os jogaderes entoartam of hino macional.

Va sala, alguna atrapalhador ma letra acompanhavam, can tande com renseréricia.

Adona da casa felinmente chegor. Trajia um pacotinho na

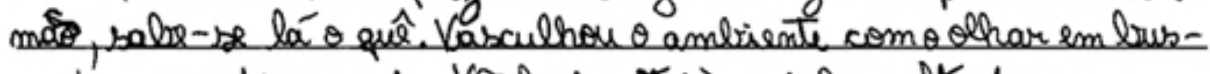

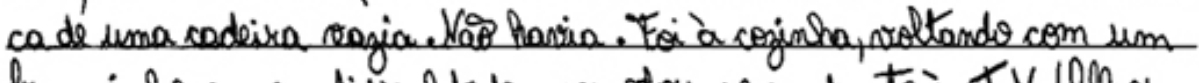
banquinhos, con dificuldade, acomedor-se em frente a $T V$. (Whor

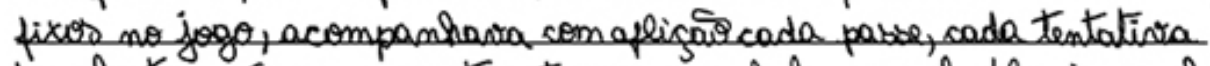
de aol. Foi ar que um grito entror com a loola no gol. $x$ legria geral. 2 mulher imposséroel cotreu para a foente da caba. Hecta de fajer uso do conterídu do pacotinho que nô largara o tempo todo. Ou-

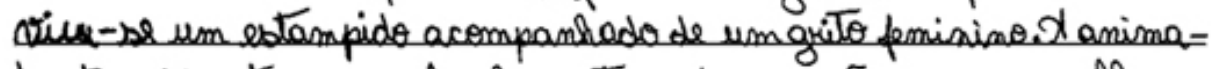
da tricedora tente uma bombra estourada ma mäe que quase the custor algum dedo. Foi aquele corre-corre. Todos queriam saber de talhes do ecerrido s prestar bolidariedade. Eentretanto, $\theta$ pequeno acidente nao desanimor a torcedora que, apos um curatioro doméstico, lá estarra ela diante da TV para, mo segundo tempo do jogo, $c \theta-$ memorar mais um gol da selecore.

Pois bem, prometo contar em outra oporturidade $\theta$ dia beguinte da feliz, mas ressacada torcedora do Brasil.

M.B.S., aluna-autora

cadernoscenpec | São Paulo | v.2 | n.1 | | julho 2012 
No texto 3 o autor construiu um narrador-personagem cuja narrativa tem como foco as ações e reações de outra personagem - a mãe. As características dessa personagem (mãe dedicada às tarefas domésticas; surpreendente como torcedora inspirada, aflita e animada; pessoa agregadora na comunidade), suas ações (arrumação da casa para receber os vizinhos; compra das bombinhas; comemoração do gol; realização do curativo) e os elementos que caracterizam o tempo (um dia de jogo do Brasil na Copa do Mundo) e o cenário (a casa da personagem) da narrativa foram introduzidos no decorrer do texto e apresentados à medida que a narrativa progredia. Assim, além de esse texto nos permitir observar a descrição funcionando como parte da narração, mostra que muitos dos elementos elencados no roteiro para avaliação da crônica proposto pelo Caderno estão devidamente contemplados.

Dentre os elementos elencados no roteiro, destaca-se a intenção ou o propósito comunicativo do autor: provocar surpresa e admiração no leitor a partir de um olhar carinhoso, surpreso e admirador em relação à mãe. Além disso, o texto permite refletir sobre a mulher-mãe desempenhando outros papéis sociais (torcedora de futebol) e sobre o olhar surpreso e descobridor do filho/da filha em relação ao jogo desses papéis.

Em relação ao conteúd o temático, podemos assinalarque o recorte selecionado pelo autor do Texto 3 está adequado ao tema geral do concurso, uma vez que focaliza as ações da mãe/personagem no conjunto de práticas socioculturais da vizinhança e, de modo mais amplo, de parte do povo brasileiro ("pátria de chuteiras"). Isso porque "O lugar onde vivo" pode ser apresentado ao leitor sob enfoques muito particulares. Pode restringir-se à casa e à vizinhança (como no texto 3) e pode também restringir-se a uma sala de aula, um quarto da casa, um bar, uma igreja ou uma loja, como em outros textos da amostra. Não há necessidade de "o lugar" referir-se a uma cidade ou a um bairro, como a maior parte dos textos procurou fazer.

Como já indicamos anteriormente, é possível que o foco volte-se para a cidade ou para o bairro em função da expectativa de que o texto tenha como interlocutores os avaliadores que desconhecem a realidade do autor. $A$ produção textual dirigida à comunidade escolar, por outro lado, permite que o recorte do cotidiano seja mais focalizado em situações mais próximas dos interlocutores (alunos/autores e leitores/pais, colegas, professores).

Nesse sentido, vale salientar que o recorte adotado no texto 3 e os recursos estilísticos utilizados para narrar fazem com que a narrativa cumpra seu objetivo independentemente da necessidade de referência a um lugar 
específico. Considerando o valor e as expectativas atribuídos à Copa do Mundo no Brasil, essa narrativa poderia ser ambientada em muitos lugares do Brasil. É essa característica de o texto abordar aquilo que é próprio da vida humana, independente da fixação em um lugar, que viabiliza a permanência da crônica. O texto não se fixa no circunstancial, mas extrapola para além do que é transitório. Fala sobre aquilo que é, em certa medida, repetível/ observável com diferentes sujeitos em distintos lugares. E o autor do texto ainda apresenta a possibilidade de o leitor refletir - para além da magia, do encantamento do futebol da Seleção Brasileira na Copa do Mundo, que transforma a mãe na surpreendente mãe-torcedora - sobre os modos como se dão as relações nos diferentes arranjos entre vizinhos em diferentes lugares: “Na nossa rua” é assim. Mas pode ser diferente em outros lugares.

Dessa forma, observamos que o texto 3 aproxima-se das orientações apresentadas no Caderno $A$ ocasião faz o escritor e permite-nos recuperar o percurso de didatização do gênero crônica desse material. Um dos aspectos em que se pode observar esse percurso, no que se refere à descrição dos cenários, é a posição do observador em relação ao que é descrito. Muitos textos, como o texto 3, (re)constroem o cenário de tal forma que é possível acompanhar os movimentos do observador como se estivéssemos ao seu lado ou como se pudéssemos ver com seus olhos. No texto 3, observamos a mãe nas tarefas domésticas, na procura por um lugar para sentar, na comemoração do gol.

Em outros textos da amostra a adequação do foco narrativo permite que partilhemos da visão do observador: que entremos no ônibus apertado e nos espremamos entre os passageiros até chegar ao fundo do transporte; que caminhemos pela praça, por entre as bancas da feira ou por entre as árvores, até chegar ao outro lado; que observemos a rua desde uma ponta à outra; caminhemos pelas ruas do bairro em companhia do observador. Nesses textos, o observador descreve cenário e personagens para compor a narração; e, tanto na narração quanto na descrição, podemos discernir o ponto de vista a partir do qual observa e também a dimensão do seu campo de visão.

Outros exemplares da amostra, no entanto, não permitem ao leitor dimensionar bem o campo de visão do narrador. O observador que nos conduz pela narração e/ou descrição, sem indicação de qualquer movimento do observador, tem seu campo de visão ampliado a ponto de descrever ou narrar algo que, da posição de observação inicial em que se apresentava no texto, dificilmente poderia ver. 0 ponto de vista do observador, ou seu 
campo de visão, não é adequado à descrição ou à narração presente no texto, pois não apresenta verossimilhança (concebida aqui como coerência), seja interna (dentro da própria narrativa), seja externa (na relação entre texto e vida). Esses textos apresentam problemas em relação ao foco e ao campo de visão de observador; dessa forma, merecem atenção especial no processo de didatização do gênero, especialmente no que se refere à reescrita. É visando atingir esse tipo de problema que o Caderno formula a seguinte questão orientadora da reescrita: "O enredo da crônica está bem desenvolvido, coerente?” (CENPEC, 2010, p. 124)

Outro aspecto analisado na amostra, e em particular neste texto 3, referese à produção do texto como relato/narrativa de experiência, relato de algum evento observado, sem, contudo, chegar a caracterizar uma narrativa literária. Nesses textos, predomina o relato de alguma cena que o autor observou ou da qual participou. No relato, basta ao autor narrar/relatar o que observou ou o que vivenciou. Não há necessidade de construir uma narrativa que apresente algum elemento surpresa ou algum conflito e um posterior desfecho. Na crônica literária, ao contrário do relato, a narrativa deve ser construída de modo que o enredo contemple uma surpresa, uma tensão ou um conflito e o desfecho. Nas crônicas esportivas, políticas e sociais, por outro lado, predomina o relato, que pode ser seguido (ou não) por alguma estrutura argumentativa. É o relato que leva à reflexão. E esse relato, algumas vezes, está ligado a alguma notícia ou uma situação ocorrida no esporte ou na política.

No texto 3, observamos um relato ligado ao esporte, ao futebol. 0 fato social mais amplo é a Copa do Mundo. Durante o período de Copa, são frequentes as notícias jornalísticas de grupos de pessoas que se encontram para assistir juntos os jogos da Seleção Brasileira. O texto 3 recupera esse contexto mais amplo e focaliza um recorte desses encontros de torcedores a partir de um olhar bem pessoal. Na construção narrativa do texto, o autor procura criar situações surpreendentes (surpresa anunciada ao falar sobre a mãe: “incorpora o espírito da pátria de chuteiras e surpreende, quando temos a felicidade de um gol"). Para isto, o autor narra o uso do conteúdo do pacotinho depois do gol e a explosão da bomba na mão da torcedora.

No entanto, embora as escolhas linguísticas auxiliem na construção da ideia de desconhecido ("Trazia na mão um pacotinho. Sabe-se lá o quê.") e sugiram suspense e surpresa ("Hora de fazer uso do conteúdo do pacotinho que não largava o tempo todo. Ouviu-se um estampido acompanhado de um 
grito feminino 7 . A animada torcedora teve uma bomba estourada na mão que quase lhe custou algum dedo"), a informação acrescida a seguir ("o pequeno acidente não desanimou a torcedora que, após um curativo doméstico"), aparentemente contraditória com o que se relatou antes ${ }^{8}$, fragiliza ${ }^{9}$ a construção do clímax da narrativa, enfraquecendo a construção da crônica literária e produzindo um relato.

É interessante observarmos que os relatos situam no tempo as experiências vividas e, portanto, utilizam estruturas narrativas que marcam o desenrolar e a conclusão das experiências. Assim, os pretéritos perfeito e imperfeito são característicos tanto dos relatos quanto das crônicas. Os relatos, no entanto, embora permitam ao leitor recuperar um certo acabamento da experiência e, portanto, do recorte que se faz da vida, muitas vezes dificultam o exercício que é próprio da ficção: vasculhar, conhecer e refletir sobre os pensamentos e sentimentos daqueles que estão envolvidos nessas experiências, enfim, dos personagens.

No texto 3, ainda que se trate de um relato, as emoções vivenciadas pelos personagens e produzidas no leitor estão vinculadas a outros elementos, distintos daquele que se pretende como o clímax da narrativa. Nesse texto, apreendemos e compartilhamos das emoções do filho que relata o envolvimento e as emoções da mãe com os jogos da Seleção; emoções por estar diante de uma mãe que surpreende nas ações. Acompanhamos as emoções da torcedora que, animada e ansiosa, prepara o evento social da torcida em conjunto, que foge dos seus padrões de comportamento e inova em função de seu apreço pela Seleção. No entanto, não acompanhamos muito das emoções vividas em função do estouro da bomba. 0 relato faz parecer que foi algo menor, pouco significativo, se comparado com a importância do jogo, porque o tom da narrativa em relação ao depois do estouro minimiza e enfraquece o fato.

Assim, outro aspecto que chama a atenção na amostra é a caracterização do tom da crônica. A escolha das palavras imprime a alguns dos textos um tom

É interessante observar que o autor opta por manter essa sentença concisa e sem a informação da causa do grito. Essa causa só é apresentada na sentença seguinte. Essa escolha da estrutura das sentenças auxilia a criar o efeito de suspense e surpresa.

Parecem inconsistentes as seguintes informações: houve um estouro de uma bomba na mão da personagem, que quase perdeu um dedo; no entanto, o acidente foi pequeno e um curativo doméstico resolveu o problema. As escolhas feitas pelo autor geram uma certa incoerência interna no texto.

Essa fragilidade fica acentuada pela conclusão do texto: "Pois bem, prometo contar em outra oportunidade o dia seguinte da feliz, mas ressacada torcedora do Brasil”. 
crítico, humorístico, irônico, lírico e até saudosista. No texto 3, por exemplo, há um misto de surpresa e admiração. No entanto, a maioria dos textos da amostra apenas relata ou descreve um acontecimento, sem utilizar recursos linguísticos que pudessem dar um tom ao texto.

Os propósitos do autor em relação a seus leitores podem orientá-lo no tom de seu texto e, portanto, nas escolhas linguístico-estilísticas (escolhas de vocabulário, de tamanhos de frases, de recursos de pontuação) a serem feitas (BAKHTIN, 2003a). Querer emocionar, divertir, provocar reflexão ou, de certa forma, persuadir o leitor, orienta as escolhas do autor para se referir ao e para descrever o evento narrado. Voltado para o lugar de publicação e o perfil de um determinado leitor, o propósito do autor orienta as seleções de palavras e de estilo de linguagem. No entanto, para isso, é preciso que o autor tenha claro que está escrevendo para um leitor e que saiba os efeitos que quer provocar neste. A construção dos efeitos de humor e do tom lírico que alguns textos apresentam decorre da consciência de que eles serão lidos e de que a leitura deve provocar no leitor sensações e reflexões, como aquelas que a observação do cotidiano despertou nos autores.

Assim, as análises nos permitem concluir que o direcionamento dos textos a distintos interlocutores (comunidade escolar e avaliadores), explicitado na orientação para produção textual, pode contribuir para que os alunos produzam textos que se afastem das orientações do Caderno do Professor. Ao tratar do tema "O lugar onde vivo", muitos alunos produziram textos predominantemente descritivos (como os textos 1 e 2), visando apresentar seu lugar (cidade, bairro, rua) a interlocutores que desconhecem sua realidade. Associada a esse propósito de apresentação do lugar, parece haver uma dificuldade de focalização e recorte de um detalhe do cotidiano (do tema), de modo que são produzidos textos que, além de predominar a descrição, procuram apresentar o todo desse lugar. Nesses textos descritivos a narração é secundária, quando não inexistente.

Considerando a amostra de textos como um todo, observamos que, diferentemente dos textos descritivos, um outro conjunto de textos aproximase das orientações do Caderno. Muitos deles, embora não se caracterizem como crônicas literárias, constituem-se como relatos e podem ser classificados como crônicas (como o texto 3, uma crônica-narrativa). Em muitas delas, que parecem dialogar principalmente com a comunidade escolar, os autores constroem adequadamente o tom do texto e o recorte do tema, focalizando o cotidiano sob um ponto de vista particular. Esse ponto de vista é apreendido pelo leitor por meio do tom do texto. 
Em nossa análise identificamos, em relação aos textos predominantemente descritivos e aqueles com a pretensão de descrição do todo, um afastamento das orientações do Caderno do Professor. Esse afastamento pode nos levar a refletir sobre um aspecto constitutivo do programa: espera-se que o processo de formação de professores extrapole o concurso da Olimpíada, promovendo a formação de professores para o processo de ensino/aprendizagem de produção textual na escola. Nessa formação, orienta-se que as produções de textos na escola sejam voltadas para a comunidade escolar, com efetiva circulação dos textos. No entanto, uma vez que compõe o material formador para a Olimpíada, que veicula os critérios para avaliação do texto em função também desse concurso e, sobretudo, que chega às mãos dos professores em virtude da Olimpíada, o Caderno pode ser fortemente associado ao concurso, levando o professor a orientar seus alunos a escrever para os avaliadores.

Quanto aos textos que podem ser caracterizados como crônicas, embora muitos não sejam inseridos no conjunto de crônicas literárias, assinalamos a adequação ao tema e a adequada focalização em um detalhe do cotidiano, associadas aos recursos linguísticos que definem o tom do texto. Esses aspectos permitem relacionar os textos ao encaminhamento pedagógico da sequência didática apresentada no Caderno, também naquilo que pode ser considerada a abertura do Caderno para a autonomia do professor. Nesse sentido, embora o Caderno enfatize a leitura e a produção de crônicas literárias e as análises apontem a produção de outros tipos de crônicas, as análises dos textos permitem-nos apontá-los como indícios de que é efetivo o processo formador desenvolvido pelo programa. 


\section{Different everyday photographs: the chronicle genre at the Olympics}

\section{ABSTRACT}

This paper analyzes chronicles produced by Brazilian students who took part in the Olympics in 2010. Initially, using Bakhtinian studies, a reflection on the chronicle is attempted based on educational-methodological guidelines provided for teaching production of this genre in the teacher training material at the Olympics - Teacher's Book Opportunity makes the writer. Next, using genre concepts of discourse and dialogism, some of the texts produced by candidates are analyzed. The analysis indicates that many texts dialogue with the guidelines in the Teacher's Book, featuring compositional elements of the genre explained in this material. Other texts show some genre characteristics that are not covered in the material, but they can be identified in texts of this genre published in newspapers.

\section{Keywords:}

Chronicle. Bakhtinian studies. Written production. Teacher training. 


\section{REFERÊNCIAS}

ANDRADE, Carlos Drummond de. Uma prosa (inédita) com Carlos Drummond de Andrade. Caros Amigos, São Paulo, n. 29, p. 12-15, ago. 1999.

ARRIGUCI JR., David. Enigma e comentário: ensaios sobre literatura e experiência. São Paulo: Cia. das Letras, 1987.

BAKHTIN, Mikhail. O problema do texto na linguística, na filologia e em outras ciências humanas. In: BAKHTIN, Mikhail. Estética da Criação Verbal. 4. ed. São Paulo: Martins Fontes, 2003b. p. 307-335.

BAKHTIN, Mikhail. Os Gêneros do Discurso. In: BAKHTIN, Mikhail. Estética da Criação Verbal. 4. ed. São Paulo: Martins Fontes, 2003a. p. 261-306.

BRASIL. Ministério da Educação. Secretaria de Educação Fundamental. Parâmetros curriculares nacionais: língua portuguesa. Brasília: MEC/SEF, 1998.

CANDIDO, Antonio. "A vida ao rés do chão". In: Para gostar de ler: Crônicas 5. São Paulo: Ática, 1981.

CANDIDO, Antonio. A crônica: o gênero, sua fixação e suas transformações no Brasil. Campinas: Editora da Unicamp; Rio de Janeiro: Fundação Casa Rui Barbosa, 1992.

CENPEC. A ocasião faz o escritor. Caderno do professor: orientações para produção de textos. Equipe de produção: Maria Aparecida Laginestra e Maria Imaculada Pereira. São Paulo: Cenpec, 2010. Coleção da Olimpíada.

MADI, Sonia. “Escrita não é um dom”. Na Ponta do Lápis, São Paulo: Cenpec, v. 1, n. 1, p. 14-15, maio/jun. 2005.

SÁ, Jorge de A. Crônica. São Paulo: Ática, 1985. (Coleção Princípios).

Recebido em: FEVEREIRO de 2012.

Aprovado em: MAIO de 2012. 